\title{
Impact of effective regurgitant orifice area on outcome of secondary mitral regurgitation transcatheter repair
}

\author{
Nicole Karam ${ }^{1,2} \cdot$ Mathias Orban ${ }^{2,3} \cdot$ Daniel Kalbacher $^{4} \cdot$ Christian Butter $^{5} \cdot$ Fabien Praz $^{6} \cdot$ Edith Lubos $^{4}$. \\ Marwin Bannehr ${ }^{5}$. Mohammad Kassar ${ }^{6}$. Aniela Petrescu ${ }^{7}$. Christos lliadis ${ }^{8}$. Matthias Unterhuber ${ }^{9}$. \\ Anouk Asselin ${ }^{1} \cdot$ Holger Thiele $^{9} \cdot$ Roman Pfister $^{8} \cdot$ Stephan Windecker $^{6} \cdot$ Philipp Lurz $^{9} \cdot$ Stephan von Bardeleben $^{7}$. \\ Jörg Hausleiter ${ }^{2,3}$. for the EuroSMR investigators
}

Received: 18 October 2020 / Accepted: 16 January 2021 / Published online: 4 March 2021

(c) The Author(s) 2021

\begin{abstract}
Objectives To assess the value of effective regurgitant orifice (ERO) in predicting outcome after edge-to-edge transcatheter mitral valve repair (TMVR) for secondary mitral regurgitation (SMR) and identify the optimal cut-off for patients' selection. Methods Using the EuroSMR (European Registry of Transcatheter Repair for Secondary Mitral Regurgitation) registry, that included patients undergoing edge-to-edge TMVR for SMR between November 2008 and January 2019 in 8 experienced European centres, we assessed the optimal ERO threshold associated with mortality in SMR patients undergoing TMVR, and compared characteristics and outcomes of patients according to baseline ERO.

Results Among 1062 patients with severe SMR and ERO quantification by proximal isovelocity surface area method in the registry, ERO was $<0.3 \mathrm{~cm}^{2}$ in 575 patients (54.1\%), who were more symptomatic at baseline (NYHA class $\geq$ III: $91.4 \%$ vs. $86.9 \%$, for ERO $<$ vs. $\left.\geq 0.3 \mathrm{~cm}^{2} ; P=0.004\right)$. There was no difference in all-cause mortality at 2-year follow-up according to baseline ERO ( $28.3 \%$ vs. $30.0 \%$ for ERO $<$ vs. $\left.\geq 0.3 \mathrm{~cm}^{2}, P=0.585\right)$. Both patient groups demonstrated significant improvement of at least one NYHA class $(61.7 \%$ and $73.8 \%, P=0.002)$, resulting in a prevalence of NYHA class $\leq$ II at 1 -year follow-up of $60.0 \%$ and $67.4 \%$ for ERO $<$ vs. $\geq 0.3 \mathrm{~cm}^{2}$, respectively $(P=0.05)$.

Conclusion All-cause mortality at 2 years after TMVR does not differ if baseline ERO is $<$ or $\geq 0.3 \mathrm{~cm}^{2}$, and both groups exhibit relevant clinical improvements. Accordingly, TMVR should not be withheld from patients with $E R O<0.3 \mathrm{~cm}^{2}$ who remain symptomatic despite optimal medical treatment, if TMVR appropriateness was determined by experienced teams in dedicated valve centres.
\end{abstract}

Keywords Mitral regurgitation $\cdot$ Effective regurgitant orifice area $\cdot$ Edge-to-edge repair $\cdot$ Outcome $\cdot$ Heart failure with reduced ejection fraction

Nicole Karam and Mathias Orban contributed equally to this work.

Members of the "EuroSMR registry" are listed in

acknowledgement section.

Jörg Hausleiter

joerg.hausleiter@med.uni-muenchen.de

1 Department of Cardiology and Paris Cardiovascular Research Center (INSERM U970), European Hospital Georges Pompidou, Paris, France

2 Medizinische Klinik und Poliklinik I, Ludwig Maximilians Universität München, Munich, Germany

3 Partner Site German Center for Cardiovascular Disease (DZHK), Munich Heart Alliance, Munich, Germany

4 Klinik für Kardiologie, UKE Hamburg, Universitäres Herz- und Gefäßzentrum, Hamburg, Germany
5 Department of Cardiology, Heart Center Brandenburg and Brandenburg Medical School, Bernau, Germany

6 Department of Cardiology, University Hospital, University of Bern, Bern, Switzerland

7 Mainz University Hospital, University of Mainz, Mainz, Germany

8 Department III of Internal Medicine, Heart Center, University of Cologne, Faculty of Medicine and University Hospital Cologne, Cologne, Germany

9 Department of Cardiology, Heart Center Leipzig at University of Leipzig, Leipzig, Germany 


\section{Introduction}

Chronic secondary mitral regurgitation (SMR) is a frequent finding in the setting of heart failure with reduced ejection fraction (HFrEF), and is associated with adverse prognosis. Since SMR is only one component of the left heart disease, mitral valve treatment may not be by itself curative, and the best therapy for chronic SMR is unclear. The benefit of mitral surgery in this setting has not been clearly demonstrated, and the majority of these patients have multiple complex comorbidities and are denied surgery in clinical practice [1,2].

Edge-to-edge transcatheter mitral valve repair (TMVR) has been shown to be an effective and safe therapeutic option in patients with primary MR at high surgical risk [3]. In SMR, results from real-life registries and three retrospective studies have shown promising initial results, including a potential mortality benefit over isolated optimal medical treatment (OMT) [4-8]. Recently, two prospective randomized trials assessed the benefit of TMVR on top of OMT in patients with severe SMR: the French Percutaneous Repair with the MitraClip Device for Severe Functional/Secondary Mitral Regurgitation (MITRA-FR) trial, which showed no benefit from TMVR on top of OMT [9], and the American Cardiovascular Outcomes Assessment of the MitraClip Percutaneous Therapy for Heart Failure Patients with Functional Mitral Regurgitation (COAPT) trial, which demonstrated significant reductions in mortality and hospitalisations for heart failure as well as improvements in quality of life $[10,10]$. One of the potential explanations that were discussed for the observed discrepancies in outcomes is the difference in effective regurgitant orifice (ERO) in each study: mean baseline ERO was $0.31 \mathrm{~cm}^{2}$ in MITRA-FR, vs. $0.41 \mathrm{~cm}^{2}$ in COAPT $\mathrm{cm}^{2}$, which led to a questioning of the yield of TMVR in the setting of low ERO (mainly $<0.3 \mathrm{~cm}^{2}$ ), even though guidelines advocate for an integrative approach to assess the severity of MR.

Accordingly, the aim of this study was two-fold: (1) to compare the characteristics and outcomes of SMR patients undergoing edge-to-edge TMVR in the retrospective EuroSMR (European Registry of Transcatheter Repair for Secondary Mitral Regurgitation) registry, according to the ERO threshold, and (2) to assess the yield of ERO in selecting candidates for TMVR, and eventually identify an optimal ERO threshold associated with mortality in SMR patients undergoing TMVR.

\section{Methods}

\section{Patients' cohort}

The EuroSMR registry is a large, retrospective registry including patients undergoing TMVR for SMR using the MitraClip ${ }^{\circledR}$ device (Abbott Structural Heart, Santa Clara,
CA, USA) between November 2008 and January 2019 in 8 experienced European centres (Munich, Hamburg, BerlinBernau, Bern, Mainz, Cologne, Leipzig, and Paris-Pompidou). All patients were symptomatic despite OMT, defined as maximally tolerated guideline-directed medical therapy, with cardiac resynchronization therapy when indicated. A heart team consensus was necessary before TMVR to evaluate the best treatment option for the individual patient. One main operator, with a secondary operator, performed the procedures in most centres, leading to a number of operators of less than 16. The study was registered at Deutsches Register Klinischer Studien (DRKS00017428).

Patient and Public Involvement: patients were not involved in the design and conduction of the study.

\section{Technical aspects}

The procedural steps of TMVR using MitraClip ${ }^{\circledR}$ have been previously described $[12,13]$. In brief, the procedure is performed under general anaesthesia with fluoroscopic and transoesophageal echocardiographic guidance. The transcatheter edge-to-edge repair system is introduced via the femoral vein, and advanced to the left atrium through a transseptal puncture. The device is then aligned perpendicular to the mitral valve plane, with the MitraClip arms perpendicular to the line of coaptation. The mitral leaflets are grasped and the device is closed, resulting in fixed approximation of the mitral leaflets. One or several clips might be needed to achieve optimal result.

\section{Data collection}

Collected data included demographic data (age and sex), medical history, and echocardiographic data. All echocardiograms were performed and analysed by experienced operators at each site. All patients underwent transthoracic and transoesophageal echocardiography before TMVR. Baseline evaluation of MR severity was performed using an integrative approach including quantitative [ERO and regurgitant volume by proximal isovelocity surface area (PISA) method] and semiquantitative parameters (vena contracta width averaged in long-axis and commissural views) as well as an assessment of the left ventricle using left ventricular ejection fraction (LVEF) and volumes (Simpson's biplane summation of disc technique). The PISA radius was measured as the distance from the threshold of color Doppler aliasing (abrupt change in color by shifting the baseline of color scale in the direction of the regurgitant jet) to the jet orifice (Supplementary Fig. 1). MR was considered severe according to these combined criteria in all patients included in the registry. Symptomatic status was assessed using the New York Heart Association (NYHA) functional class. Patients had regular follow-ups in their respective hospitals. 
Available follow-up data included survival status, NYHA functional class at 1 year and 2 years, and evaluation of MR grade through either outpatient visit or telephone interviews with the patient or patient's relatives.

Data collection and follow-ups were performed according to protocols of the participating centres, and in line with local ethical regulations and adhered to international rules for scientific studies as well as the Helsinki principles. Patients needed to be legal of age and able to consent. The authors had full access to data and designed the statistical analysis, had final responsibility for the decision to submit the manuscript for publication, and vouch for the accuracy and completeness of the data and the analyses.

\section{Statistical analysis}

Spline curves, assessing the relation between ERO and mortality, were performed in order to identify the optimal cut-off for ERO. In case of absence of cut-off, the median ERO was intended to be used as a cut-off for the analyses. Supplementary analyses were pre-specified, using the cut-offs of 0.2 and $0.4 \mathrm{~cm}^{2}$, according to current guidelines.

Patients' characteristics and outcomes were described according to their baseline ERO. The primary outcome was survival rate at 2 years. NYHA functional class was assessed and compared between the two ERO groups at baseline and last follow-up. Variables were described using medians [and interquartile ranges (IQR)] as well as means and standard deviations for continuous measures, and counts and proportions for categorical measures. Normality of presented variables was assessed using the Shapiro test and graphical distribution. Comparisons between groups were performed using Chi-square for categorical variables, and Student's t-test or Mann-Whitney-Wilcoxon test for continuous variables, as appropriate. Cumulative survivals at two year were analysed using Kaplan-Meier models and compared using Cox regression. The cumulative incidence of the secondary end-point was compared between the two ERO groups using a Cox regression model. All $P$ values were calculated using 2 -sided tests, and a significance level of 0.05 was used to declare statistical significance. Statistical analyses were performed using R software version 3.5.1 (R Project for Statistical Computing). This study is reported according to Strengthening The Reporting of Observational studies in Epidemiology guidelines [14].

\section{Results}

A total of 1237 patients with severe SMR underwent TMVR in the participating centres and were included in EuroSMR. In 1062 patients, ERO quantification before TMVR was available, which defined the study population for the current analysis. Baseline characteristics of the global population are presented in Table 1. Median age of the patients was 76.0 (IQR: 69.0-80.1) years, with 387 women (36.5\%). Overall, 943 patients $(89.4 \%)$ were in NYHA class III or IV at the time of the procedure. They presented with atrial fibrillation in 686 patients (64.7\%), a prior stroke in 98 patients $(9.2 \%)$, and a chronic pulmonary disease in 174 patients (16.4\%). Regarding surgical risk, median EuroSCORE II was 6.7\% (IQR: $3.9-11.9 \%)$. The aetiology of SMR was ischemic in 515 patients $(51.6 \%)$.

Baseline echocardiographic parameters are described in Table 2. Median ERO was $0.28 \mathrm{~cm}^{2}$ (IQR: $0.20-0.39$ ). Median LVEF was $34.0 \%$ (IQR: $25.0-44.0 \%$ ) with a median LV end-diastolic volume of $170 \mathrm{ml}$ (IQR: 123-225 ml) and end-systolic volume of $110 \mathrm{ml}$ (IQR: $70.0-160.0 \mathrm{ml}$ ). The median vena contracta diameter was $6.8 \mathrm{~mm}$ (IQR: $4.8-8.0 \mathrm{~mm})$.

\section{Characteristics according to ERO}

Spline curve analysis assessing the relation between ERO and mortality revealed a flat curve, without identification of an optimal cut-off for ERO (Fig. 1). Accordingly, an ERO $<$ and $\geq 0.3 \mathrm{~cm}^{2}$ was applied to evaluate the impact of ERO on mortality in this study, which is the next round value close to the median ERO of $0.28 \mathrm{~cm}^{2}$.

Baseline clinical characteristics of patients according to baseline ERO are presented in Table 1. The ERO was $<0.3 \mathrm{~cm}^{2}$ in 575 patients ( $54.1 \%$ ), and $\geq 0.3 \mathrm{~cm}^{2}$ in 487 patients (45.9\%). Overall, there was no difference between the two groups except for a lower proportion of men in the lower ERO group $\left(60.7 \%\right.$ vs. $66.7 \%$, for ERO $<$ vs. $\geq 0.3 \mathrm{~cm}^{2}$, respectively, $P=0.050$ ), and a more frequent ischemic aetiology $(54.9 \%$ vs. $47.9 \%, P=0.031)$. Patients in the lower ERO group were more symptomatic with a higher proportion of patients having a NYHA class of III or IV at baseline (91.4\% vs. $86.9 \%, P=0.004$; Fig. 2 ).

Regarding baseline echocardiographic parameters, patients in the lower ERO group had smaller LV volumes with a smaller end-diastolic LV volume $(166 \mathrm{ml}$ vs. $174 \mathrm{ml}$, for ERO $<$ vs. $\geq 0.3 \mathrm{~cm}^{2}$, respectively, $\left.P=0.002\right)$. Their vena contracta diameters were smaller $(6.5 \mathrm{~mm}$ vs. $7.0 \mathrm{~mm}$, $P<0.018)$. Notably, there was no difference in LVEF between the two groups (Table 2).

\section{Outcome according to ERO}

Post-procedural MR reduction of at least one grade was observed in $95.8 \%$ of patients $(96.4 \%$ vs. $94.6 \%$, for ERO < vs. $\geq 0.3 \mathrm{~cm}^{2}$, respectively, $P=0.530$ ). Median MR reduction was of 2 grades [IQR 2.0-3.0] in patients with ERO $<0.3$, and 2.0 [IQR: 1.5-3.0] in patients with $\mathrm{ERO} \geq 0.3(P=0.758)$. This improvement was maintained 
Table 1 Baseline clinical characteristics according to ERO

\begin{tabular}{|c|c|c|c|c|}
\hline & Overall 1062 patients & $\mathrm{ERO}<0.3575$ patients & $E R O \geq 0.3487$ patients & $P^{*}$ \\
\hline Age, years & $76.0[69.0-80.1]$ & $76.0[69.0-80.2]$ & $75.0[69.0-80.1]$ & 0.109 \\
\hline Male sex, $n(\%)$ & $673(63.5 \%)$ & $348(60.7 \%)$ & $325(66.7 \%)$ & 0.050 \\
\hline EuroSCORE II, \% & $6.7[3.9-11.9]$ & $6.6[3.9-11.6]$ & $6.9[3.9-12.5]$ & 0.521 \\
\hline Ischemic aetiology, $n(\%)$ & $515(51.6 \%)$ & $290(54.9 \%)$ & $225(47.9 \%)$ & 0.031 \\
\hline Prior CABG, $n(\%)$ & $174(17.5 \%)$ & $98(18.8 \%)$ & $76(16.1 \%)$ & 0.299 \\
\hline Previous PCI, $n(\%)$ & $346(42.8 \%)$ & $182(44.9 \%)$ & $164(40.7 \%)$ & 0.251 \\
\hline Prior myocardial infarction, $n(\%)$ & $261(24.9 \%)$ & $139(24.5 \%)$ & $122(25.4 \%)$ & 0.806 \\
\hline Prior stroke, $n(\%)$ & $98(9.2 \%)$ & $53(9.2 \%)$ & $45(9.2 \%)$ & 0.999 \\
\hline Chronic Pulmonary Disease, $n(\%)$ & $174(16.4 \%)$ & $98(17.1 \%)$ & $76(15.7 \%)$ & 0.587 \\
\hline Atrial fibrillation, $n(\%)$ & $469(62.9 \%)$ & $274(61.9 \%)$ & $195(64.4 \%)$ & 0.573 \\
\hline $\mathrm{ICD}, n(\%)$ & $179(24.9 \%)$ & $91(26.1 \%)$ & $88(23.8 \%)$ & 0.547 \\
\hline $\mathrm{CRT}, n(\%)$ & $162(19.0 \%)$ & $79(18.6 \%)$ & $83(19.4 \%)$ & 0.845 \\
\hline $\mathrm{GFR},(\mathrm{ml} / \mathrm{min})$ & $46.1[33.0-61.1]$ & $46.0[33.0-63.1]$ & $46.2[33.0-60.0]$ & 0.730 \\
\hline NYHA class III or IV, $n(\%)$ & $943(89.4 \%)$ & $524(91.4 \%)$ & $419(86.9 \%)$ & 0.004 \\
\hline
\end{tabular}

Qualitative data are presented as $n(\%)$; quantitative data are presented as mean $\pm \mathrm{SD}$. CABG coronary artery bypass graft, $P C I$ percutaneous Coronary Intervention, ICD implantable cardioverter-defibrillator, $C R T$ cardiac resynchronization therapy, GFR glomerular filtration rate, $N Y H A$ New York Heart Association

*Parametric tests for continuous normal variables, non-parametric tests for continuous non-normal variables, $X^{2}$ for categorical variables

Table 2 Baseline clinical echocardiographic according to ERO

\begin{tabular}{|c|c|c|c|c|}
\hline & Overall 1062 patients & $\mathrm{ERO}<0.3575$ patients & $\mathrm{ERO} \geq 0.3487$ patients & $P^{*}$ \\
\hline ERO (PISA), $\mathrm{cm}^{2}$ & $0.28[0.20-0.39]$ & $0.20[0.15-0.24]$ & $0.40[0.33-0.49]$ & $<0.001$ \\
\hline RV (PISA), ml & $36.0[25.0 ; 50.0]$ & $28.0[21.6 ; 36.0]$ & $52.0[43.5 ; 67.0]$ & $<0.001$ \\
\hline Vena contracta, mm & $6.8[4.8-8.0]$ & $6.5[4.4-7.8]$ & $7.0[5.0-8.1]$ & 0.018 \\
\hline \multicolumn{5}{|l|}{ MV characteristics } \\
\hline Mean pressure gradient, $\mathrm{mmHg}$ & $1.00[1.00 ; 2.00]$ & $1.00[1.00 ; 2.00]$ & $2.00[1.00 ; 2.00]$ & 0.534 \\
\hline Antero-posterior diameter, $\mathrm{cm}$ & $3.62[3.27 ; 4.04]$ & $3.56[3.22 ; 4.00]$ & $3.80[3.39 ; 4.14]$ & 0.020 \\
\hline Tenting height, $\mathrm{cm}$ & $0.78[0.60 ; 0.98]$ & $0.75[0.57 ; 0.92]$ & $0.88[0.70 ; 1.03]$ & 0.002 \\
\hline Tenting area, $\mathrm{cm}^{2}$ & $2.78[2.14 ; 3.41]$ & $2.70[2.10 ; 3.33]$ & $2.90[2.33 ; 3.89]$ & 0.029 \\
\hline \multicolumn{5}{|l|}{ LV characteristics } \\
\hline LVEF, \% & $34.0[25.0-44.0]$ & $34.0[25.8-44.7]$ & $33.2[25.0-43.0]$ & 0.415 \\
\hline End-diastolic volume, $\mathrm{ml}$ & $170[123-225]$ & $166[118-215]$ & $174[130-240]$ & 0.002 \\
\hline End-systolic volume, $\mathrm{ml}$ & $110[70-160]$ & $108[68-154]$ & $114[74-168]$ & 0.061 \\
\hline
\end{tabular}

*Parametric tests for continuous normal variables, non-parametric tests for continuous non-normal variables, $X^{2}$ for categorical variables. $E R O$ effective regurgitant orifice, PISA proximal isovelocity surface area, $R V$ regurgitant volume, $M V$ mitral valve, $L V$ left ventricular, $L V E F$ left ventricular ejection fraction

at last follow-up with a median MR grade of 1 [IQR: 1.0-2.0] in the global population and in both ERO groups $(P=0.22)$.

Mean follow-up duration was $467 \pm 638$ days [median duration 324 (IQR: 34-730) days]. Estimated all-cause mortality rates at 1 year and 2 years were $24.0 \%$ and $29.1 \%$, respectively. There was no difference in survival at 1 year (23.3 vs. $24.9 \%, P=0.581)$ and two years $(28.3 \%$ vs. $30.0 \%$, for ERO <vs. $\geq 0.3 \mathrm{~cm}^{2}$, respectively, $P=0.585$; Fig. 3 ). Similar results were obtained with the pre-specified cut-offs of 0.2 and $0.4 \mathrm{~cm}^{2}$, and with the exact median of $0.28 \mathrm{~cm}^{2}$ used as cut-off (Supplementary Figs. 2, 3 and 4).

At 1 year, improvement by at least one NYHA class was observed in $65.4 \%$ of patients. The improvement rate was superior in patients with a higher ERO group ( $61.7 \%$ vs. $73.8 \%$, for $\mathrm{ERO}<\mathrm{vs} . \geq 0.3 \mathrm{~cm}^{2}$, respectively, $P=0.002)$. Similarly, patients in the higher ERO group were more often in NYHA class I or II $(60.0 \%$ vs. $67.4 \%$, for ERO <vs. $\geq 0.3 \mathrm{~cm}^{2}$, respectively, $P=0.05$; Fig. 2). Similar results were obtained with a cut-off of $0.4 \mathrm{~cm}^{2}(P=0.029)$, 


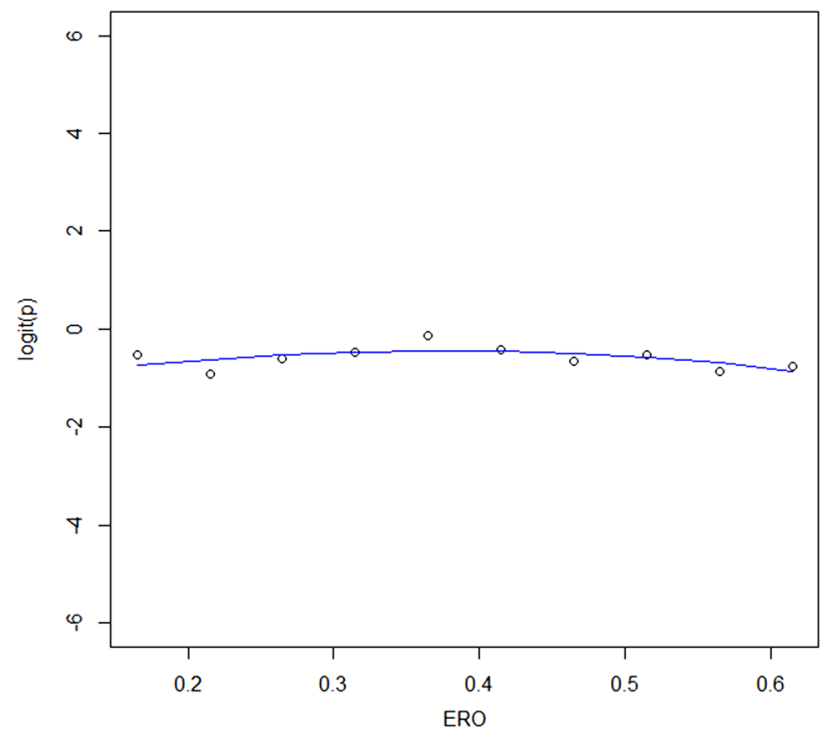

Fig. 1 Spline curve analysis assessing the Association between ERO and mortality. Spline curve analysis revealed a flat curve, without identification of an optimal cut-off for ERO. ERO effective regurgitant orifice

while there was no difference in NYHA class at last follow-up when a cut-off of $0.2 \mathrm{~cm}^{2}$ was used (Supplementary Figs. 5 and 6).

\section{Discussion}

There has been a long debate on the impact of TMVR on outcomes in patients with chronic SMR and HFrEF. While four studies, three retrospective reports and the prospective randomized COAPT trial, demonstrated a survival benefit with TMVR $[6,7,8,10]$, the prospective randomized MITRA-FR study did not [9]. These contradictory outcomes have raised a host of new questions:

1. Can the differences in outcomes between these studies be explained by differences in SMR severity as assessed by ERO?

2. Should we restrict TMVR to patients with higher ERO values?

3. Should the observed study results lead to a change of the European recommendations on the echocardiographic definition of severe SMR towards a higher ERO threshold?

The EuroSMR registry was initiated to provide further insights and answers for the raised questions. Eight European high volume centres with a long experience in the treatment of SMR by TMVR included their patients, who were treated in clinical routine, into this retrospective real-world registry. Of note, a multidisciplinary heart team assessed each individual patient before the procedure to establish the severity of MR using a multiparametric echocardiographic approach, and the appropriateness of TMVR. When compared to the COAPT-TMVR patients group, EuroSMR patients with an ERO $\geq 0.3 \mathrm{~cm}^{2}$ had several similarities
Fig. 2 NYHA Functional Class at baseline and 1-year follow-up according to baseline ERO. Patients with baseline $\mathrm{ERO}<0.3 \mathrm{~cm}^{2}$ were more frequently in NYHA class III-IV at baseline and at last follow-up, compared to patients with baseline $\mathrm{ERO} \geq 0.3 \mathrm{~cm}^{2}(P=0.002$ and $P=0.050$, respectively). $E R O$ effective regurgitant orifice, NYHA New York Heart Association

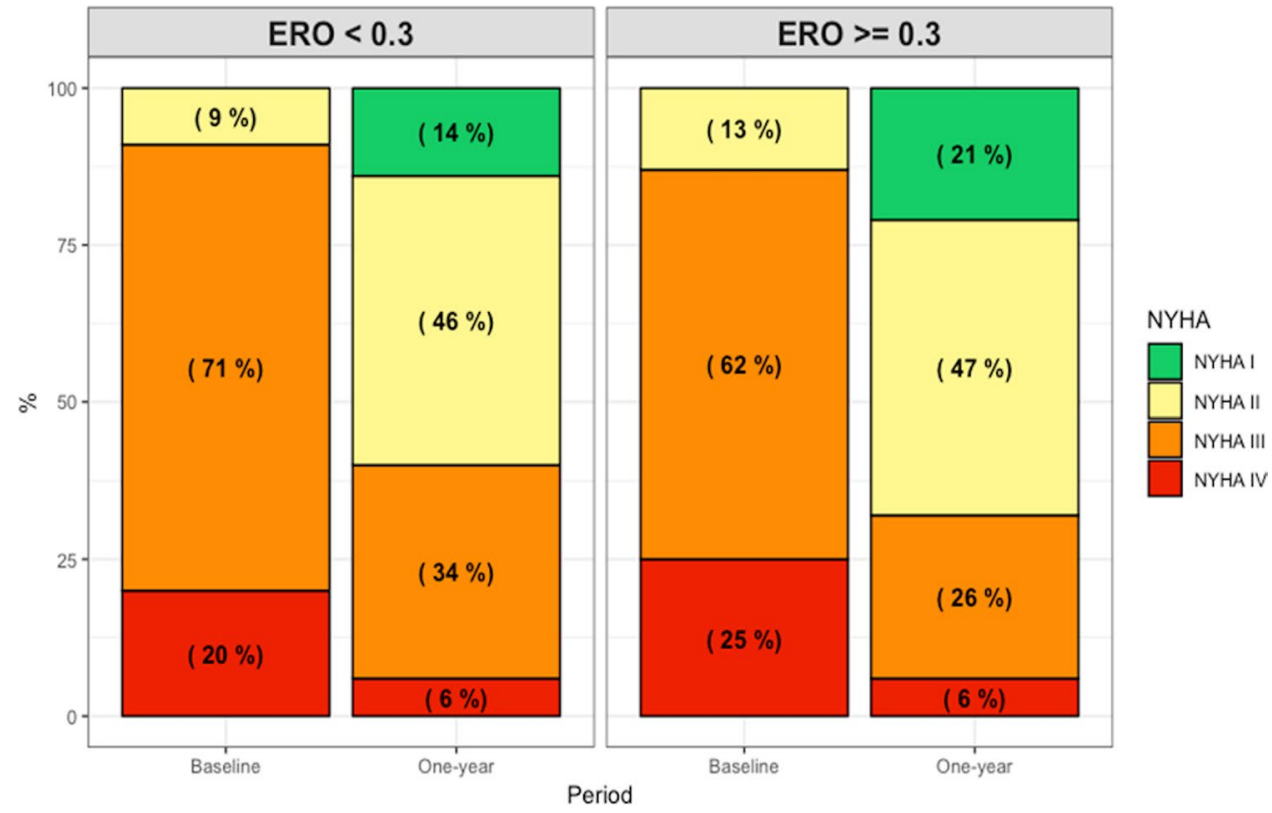


Fig. 3 Kaplan-Meier Curve for Survival Free according to Baseline ERO. There was no difference in survival rate at 2 years according to baseline ERO (Log Rank $P=0.52)$. ERO effective regurgitant orifice, $T M V R$ transcatheter mitral valve repair

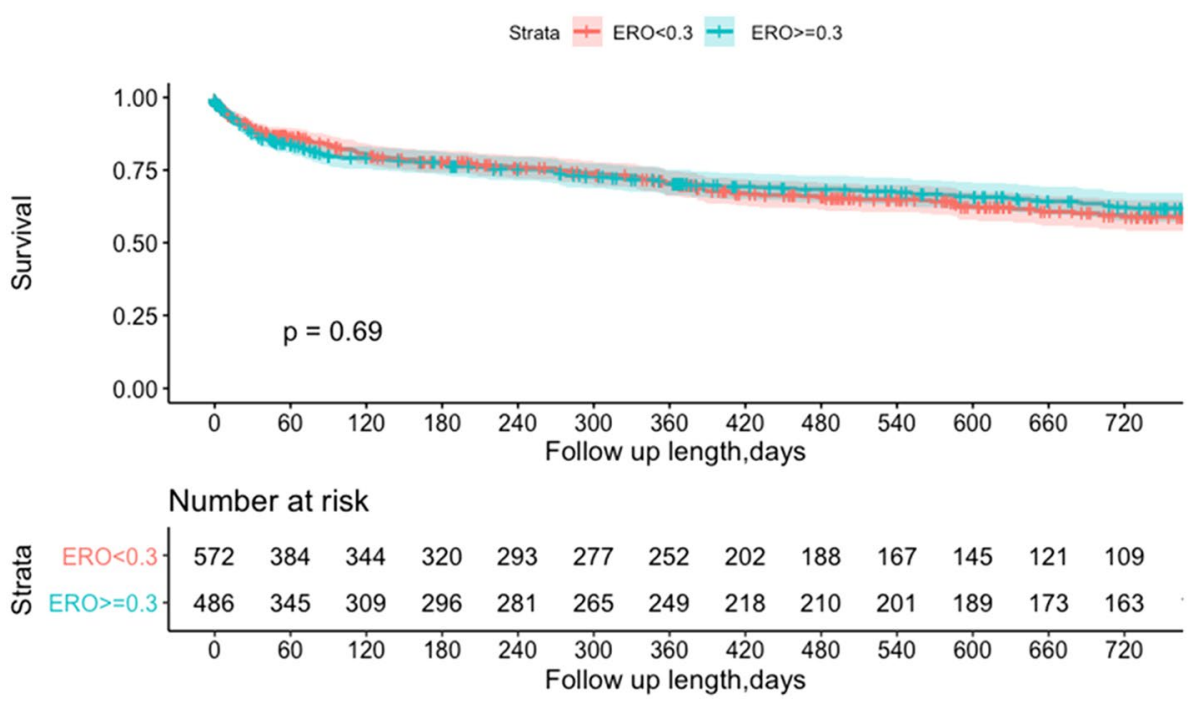

in their baseline characteristics, including ERO $\left(0.4 \mathrm{~cm}^{2}\right.$ vs. $0.41 \mathrm{~cm}^{2}$, even though not all patients in COAPT did have an ERO $>0.3 \mathrm{~cm}^{2}$ ), LVEDV (174 $\mathrm{ml}$ vs. $194 \mathrm{ml}$ ), and LV-EF (33.2\% vs. $31.3 \%$ ) for EuroSMR vs. COAPT-TMVR, respectively. Furthermore, the two-year all-cause mortality rate was comparable with $30.0 \%$ vs. $29.1 \%$ for EuroSMR vs. COAPT-TMVR, respectively [10]. Due to the lack of a control group in EuroSMR, the true benefit of TMVR in this particular European patient population remains unclear, but the similarities with the COAPT-TMVR group might indicate a comparable outcome.

The surprising finding of EuroSMR is the comparable all-cause mortality rate in patients treated with TMVR and with an ERO $<0.3 \mathrm{~cm}^{2}$, without any survival difference at 1 year and 2 years. Besides, spline curves showed a very weak relation between ERO and mortality, supporting the notion that ERO may not be an appropriate tool to predict outcome after TMVR, and that differences in ERO cannot solely explain the differences in outcomes between COAPT and MITRA-FR. Accordingly, a more integrative approach, assessing among others MR severity with additional qualitative and quantitative parameters, right heart function and clinical parameters, is needed to predict which patients with HFrEF will actually benefit from TMVR, or more importantly, in which patients TMVR is ineffective.

Quantification of SMR severity is challenging, and the interpretation of the MR severity assessment should be made with caution. LV volume and stroke volume, as determined by two-dimensional echocardiography with the use of Simpson's rule, are often underestimated, especially in patients with dilated ventricles $[15,16]$. Regarding ERO, the cut-off of $>0.2 \mathrm{~cm}^{2}$ has traditionally been used in Europe to determine severe MR since data suggested that, adverse outcomes are associated with a smaller ERO in SMR than in primary MR. This observation is explained by a smaller regurgitant volume, which may still represent a relevant regurgitant fraction in the presence of compromised LV systolic function (and low total stroke volume) adding to the effects of elevated ventricular filling pressures. However, ERO calculated by PISA is affected by valve morphology and colour flow jet characteristics [17]. PISA measurement requires accurate visualisation of the aliasing line of the isovelocity surface and the regurgitant orifice, and suboptimal images can alter the reliability of the measurement. Besides, in SMR, Doppler methods for ERO area calculations by the flow convergence method are less reproducible and may underestimate severity because of the crescent shape of the regurgitant orifice. Finally, the reliability of ERO measurement in the setting of SMR is questionable given the variability of MR throughout systole, typically in a biphasic pattern, leading to a variation in measured ERO according to the timing of assessment, with an early systolic peak, followed by a rapid decrease to a midsystolic lowest value, then a rapid increase toward a late systolic peak [18]. The current EuroSMR findings demonstrate that selected patients with ERO above but also below $0.3 \mathrm{~cm}^{2}$ benefit from TMVR, and have similar mortalities, and that it might not be reasonable to restrict TMVR to patients with ERO $>0.3 \mathrm{~cm}^{2}[1,2,19]$.

Regarding the symptomatic improvement, MITRAFR and COAPT showed a benefit of TMVR in terms of NYHA functional class. In COAPT, $72.2 \%$ of TMVR treated patients were in NYHA functional class I or II at 1-year follow-up, which compares well with the observed $68 \%$ rate of EuroSMR patients with an ERO $\geq 0.3 \mathrm{~cm}^{2}$. As for patients with ERO $\leq 0.3 \mathrm{~cm}^{2}$, the COAPT investigators recently presented the improvements in the physical exercise capacity and quality of life in patients with an ERO $\leq 0.3 \mathrm{~cm}^{2}$ and large left ventricles vs. the remainder of patients (either ERO $>0.3 \mathrm{~cm}^{2}$ or large left ventricles) [20]. In this analysis, both patient groups exhibited 
very similar improvements for both outcome parameters, indicating that also patients with smaller ERO experience a significant symptomatic benefit. This observation is also paralleled in the current EuroSMR registry with $61.7 \%$ of patients with an ERO $<0.3 \mathrm{~cm}^{2}$ demonstrating an improvement of at least one NYHA functional class at follow-up. Given this recent COAPT subgroup analysis, as well as the EuroSMR results, which both demonstrate that a large proportion of patients with severe SMR and an ERO $<0.3 \mathrm{~cm}^{2}$ will obtain a clinically relevant improvement from TMVR, TMVR should not be withheld from patients with an ERO $<0.3 \mathrm{~cm}^{2}$. However, these results should not lead to excessive TMVR in patients with ERO $<0.3 \mathrm{~cm}^{2}$. Instead, experienced multidisciplinary heart teams have to assess TMVR appropriateness using an integrative approach of clinical aspects including the patient history of heart failure and current presentation, as well as qualitative, semi-quantitative, and quantitative echocardiographic parameters for the assessment of SMR severity [21].

\section{Limitations}

Several limitations have to be acknowledged. This is an observational study without a control group, and there was no central adjudication of clinical status and echocardiographic parameters. Severity of MR was assessed using integrative approach including several echocardiographic parameters. Some of those variables, such as E wave velocity, pulmonary vein flow reversal, vena contracta area by 3D imaging or another measure of non-circular orifice were not consistently available in the database due to the absence of corelab and the retrospective multicentric nature of the registry that prevented the extensive collection of all echocardiographic parameters. All patients included were considered as under OMT, based on the local heart teams' assessment; however, there was no clinical core lab to monitor this information, and the subsequent therapeutic adjustments were not documented. Several patients were lost to follow-up, as it is often the case in multicentric retrospective registries, and we do not have the specific cause of mortality, in particular, we cannot distinguish whether mortality was due to a cardiovascular cause. Finally, a selection bias might explain the observed differences in NYHA class before TMVR, e.g., the increased severity of the symptoms might explain why patients with lower ERO underwent TMVR despite a less severe MR according to ERO. However, as discussed above, it appears important to realize that the symptomatic improvement is comparable in patients with an ERO $<$ or $\geq 0.3 \mathrm{~cm}^{2}$.

\section{Conclusion}

The large EuroSMR registry reveals that ERO is not an appropriate tool to select SMR patients likely to benefit from TMVR. Besides, all-cause mortality after edge-toedge TMVR does not differ between patients with a baseline ERO $<$ or $\geq 0.3 \mathrm{~cm}^{2}$, as long as the severity of MR was established using an integrative approach, and both groups exhibited a relevant clinical improvement, so that TMVR should not be withheld from such patients who remain symptomatic despite OMT, if the appropriateness for TMVR has been determined by an experienced heart team in dedicated heart valve centres.

Supplementary Information The online version contains supplementary material available at https://doi.org/10.1007/s00392-021-01807-0.

Acknowledgements EuroSMR investigators: Munich-Medizinische Klinik und Poliklinik I: Mathias Orban, Daniel Braun, Michael Näbauer, Stephan Massberg, Joerg Hausleiter; Hamburg_-UKE: Daniel Kalbacher, Edith Lubos, Dirk Westermann, Niklas Schofer, Sebastian Ludwig; Berlin-Bernau: Christian Butter, Marvin Bannehr; BernBern University: Fabien Praz, Stephan Windecker, Mohammad Kassar; Mainz-Mainz University Hospital: Aniela Petrescu, Stephan von Bardeleben; Cologne-Heart Center: Roman Pfister, Christos Iliadis, Stephan Baldus; Leipzig-Heart Center: Philipp Lurz, Holger Thiele, Matthias Unterhuber; Maximilian von Roeder, Thilo Noack; ParisEuropean Hospital Georges Pompidou: Nicole Karam, Tania Puscas, Alain Berrebi, Noemie Tence, Christian Latremouille.

Funding Open Access funding enabled and organized by Projekt DEAL.

\section{Compliance with ethical standards}

Conflict of interest N. Karam has received consultant fees from Abbott Vascular; M. Orban received speaker fees from Abbott Vascular. S. Windecker has received research and educational grants from Abbott, Amgen, BMS, Bayer, Boston Scientific, Biotronik, CSL, Medtronic, Edwards, Sinomed and Polares; R Pfister received financial support for attending symposia by Abbot Vascular; R S von Banderleben received Speaker fees from Abbott Vascular and Edwards Lifesciences; J. Hausleiter has received research support and speaker honoraria from $\mathrm{Ab}$ bott Vascular and Edwards Lifesciences. The other investigators have no conflicts of interest to declare.

Open Access This article is licensed under a Creative Commons Attribution 4.0 International License, which permits use, sharing, adaptation, distribution and reproduction in any medium or format, as long as you give appropriate credit to the original author(s) and the source, provide a link to the Creative Commons licence, and indicate if changes were made. The images or other third party material in this article are included in the article's Creative Commons licence, unless indicated otherwise in a credit line to the material. If material is not included in the article's Creative Commons licence and your intended use is not permitted by statutory regulation or exceeds the permitted use, you will need to obtain permission directly from the copyright holder. To view a copy of this licence, visit http://creativecommons.org/licenses/by/4.0/. 


\section{References}

1. Baumgartner H, Falk V, Bax JJ, de Bonis M, Hamm C, Holm PJ, Iung B, Lancellotti P, Lansac E, Rodriguez Muñoz D, Rosenhek R, Sjögren J, Tornos Mas P, Vahanian A, Walther T, Wendler O, Windecker S, Zamorano JL, ESC Scientific Document Group (2017) ESC/EACTS Guidelines for the management of valvular heart disease. Eur Heart J 38(2017):2739-2791. https://doi. org/10.1093/eurheartj/ehx391

2. Nishimura RA, Otto CM, Bonow RO, Carabello BA, Erwin JP, Fleisher LA, Jneid H, Mack MJ, McLeod CJ, O'Gara PT, Rigolin VH, Sundt TM, Thompson A (2017) AHA/ACC focused update of the 2014 AHA/ACC guideline for the management of patients with valvular heart disease: a report of the American College of Cardiology/American Heart Association Task Force on Clinical Practice Guidelines. Circulation 135(2017):e1159e1195. https://doi.org/10.1161/CIR.0000000000000503

3. Feldman T, Kar S, Elmariah S, Smart SC, Trento A, Siegel RJ, Apruzzese P, Fail P, Rinaldi MJ, Smalling RW, Hermiller JB, Heimansohn D, Gray WA, Grayburn PA, Mack MJ, Lim DS, Ailawadi G, Herrmann HC, Acker MA, Silvestry FE, Foster E, Wang A, Glower DD, Mauri L (2015) EVEREST II investigators, randomized comparison of percutaneous repair and surgery for mitral regurgitation: 5-year results of EVEREST II. J Am Coll Cardiol 66:2844-2854. https://doi.org/10.1016/j.jacc.2015.10.018

4. Puls M, Lubos E, Boekstegers P, von Bardeleben RS, Ouarrak T, Butter C, Zuern CS, Bekeredjian R, Sievert H, Nickenig G, Eggebrecht H, Senges J, Schillinger W (2016) One-year outcomes and predictors of mortality after MitraClip therapy in contemporary clinical practice: results from the German transcatheter mitral valve interventions registry. Eur Heart J 37:703-712. https://doi. org/10.1093/eurheartj/ehv627

5. Maisano F, Franzen O, Baldus S, Schäfer U, Hausleiter J, Butter C, Ussia GP, Sievert H, Richardt G, Widder JD, Moccetti T, Schillinger W (2013) Percutaneous mitral valve interventions in the real world: early and 1-year results from the ACCESS-EU, a prospective, multicenter, nonrandomized post-approval study of the MitraClip therapy in Europe. J Am Coll Cardiol 62:1052-1061. https://doi.org/10.1016/j.jacc.2013.02.094

6. Swaans MJ, Bakker ALM, Alipour A, Post MC, Kelder JC, de Kroon TL, Eefting FD, Rensing BJWM, Van der Heyden JAS (2014) Survival of transcatheter mitral valve repair compared with surgical and conservative treatment in high-surgical-risk patients. JACC Cardiovasc Interv 7:875-881. https://doi.org/10.1016/j. jcin.2014.01.171

7. Velazquez EJ, Samad Z, Al-Khalidi HR, Sangli C, Grayburn PA, Massaro JM, Stevens SR, Feldman TE, Krucoff MW (2015) The MitraClip and survival in patients with mitral regurgitation at high risk for surgery: a propensity-matched comparison. Am Heart J 170:1050-1059.e3. https://doi.org/10.1016/j.ahj.2015.08.004

8. Giannini C, Fiorelli F, De Carlo M, Guarracino F, Faggioni M, Giordano P, Spontoni P, Pieroni A, Petronio AS (2016) Comparison of percutaneous mitral valve repair versus conservative treatment in severe functional mitral regurgitation. Am J Cardiol 117:271-277. https://doi.org/10.1016/j.amjcard.2015.10.044

9. Obadia J-F, Messika-Zeitoun D, Leurent G, Iung B, Bonnet G, Piriou N, Lefèvre T, Piot C, Rouleau F, Carrié D, Nejjari M, Ohlmann P, Leclercq F, Saint Etienne C, Teiger E, Leroux L, Karam N, Michel N, Gilard M, Donal E, Trochu J-N, Cormier B, Armoiry X, Boutitie F, Maucort-Boulch D, Barnel C, Samson G, Guerin P, Vahanian A, Mewton N, MITRA-FR Investigators (2018) Percutaneous repair or medical treatment for secondary mitral regurgitation. N Engl J Med 379:2297-2306. https://doi. org/10.1056/NEJMoa1805374
10. Stone GW, Lindenfeld J, Abraham WT, Kar S, Lim DS, Mishell JM, Whisenant B, Grayburn PA, Rinaldi M, Kapadia SR, Rajagopal V, Sarembock IJ, Brieke A, Marx SO, Cohen DJ, Weissman NJ, Mack MJ (2018) COAPT investigators, transcatheter mitral-valve repair in patients with heart failure. $\mathrm{N}$ Engl J Med 379:2307-2318. https://doi.org/10.1056/NEJMoa1806640

11. Arnold SV, Chinnakondepalli KM, Spertus JA, Magnuson EA, Baron SJ, Kar S, Lim DS, Mishell JM, Abraham WT, Lindenfeld JA, Mack MJ, Stone GW, Cohen DJ (2019) COAPT investigators, health status after transcatheter mitral-valve repair in heart failure and secondary mitral regurgitation: COAPT trial. J Am Coll Cardiol 73:2123-2132. https://doi.org/10.1016/j.jacc.2019.02.010

12. Wunderlich NC, Siegel RJ (2013) Peri-interventional echo assessment for the MitraClip procedure. Eur Heart J Cardiovasc Imaging 14:935-949. https://doi.org/10.1093/ehjci/jet060

13. Mack MJ, Abraham WT, Lindenfeld J, Bolling SF, Feldman TE, Grayburn PA, Kapadia SR, McCarthy PM, Lim DS, Udelson JE, Zile MR, Gammie JS, Gillinov AM, Glower DD, Heimansohn DA, Suri RM, Ellis JT, Shu Y, Kar S, Weissman NJ, Stone GW (2018) Cardiovascular outcomes assessment of the MitraClip in patients with heart failure and secondary mitral regurgitation: design and rationale of the COAPT trial. Am Heart J 205:1-11. https://doi.org/10.1016/j.ahj.2018.07.021

14. von Elm E, Altman DG, Egger M, Pocock SJ, Gøtzsche PC, Vandenbroucke JP (2007) STROBE initiative, strengthening the reporting of observational studies in epidemiology (STROBE) statement: guidelines for reporting observational studies. BMJ 335:806-808. https://doi.org/10.1136/bmj.39335.541782.AD

15. Crestanello JA, Oh JK, Schaff HV (2019) Transcatheter mitralvalve repair in patients with heart failure. N Engl J Med 380:1978. https://doi.org/10.1056/NEJMc1903982

16. Stone GW, Weissman NJ, Mack MJ, COAPT Investigators (2019) Transcatheter mitral-valve repair in patients with heart failure reply. N Engl J Med 380:1980-1981. https://doi.org/10.1056/ NEJMc1903982

17. Biner S, Rafique A, Rafii F, Tolstrup K, Noorani O, Shiota T, Gurudevan S, Siegel RJ (2010) Reproducibility of proximal isovelocity surface area, vena contracta, and regurgitant jet area for assessment of mitral regurgitation severity. JACC Cardiovasc Imaging 3:235-243. https://doi.org/10.1016/j.jcmg.2009.09.029

18. Hung J, Otsuji Y, Handschumacher MD, Schwammenthal E, Levine RA (1999) Mechanism of dynamic regurgitant orifice area variation in functional mitral regurgitation: physiologic insights from the proximal flow convergence technique. J Am Coll Cardiol 33:538-545. https://doi.org/10.1016/s0735-1097(98)00570-1

19. Nishimura RA, Otto CM, Bonow RO, Carabello BA, Erwin JP, Guyton RA, O'Gara PT, Ruiz CE, Skubas NJ, Sorajja P, Sundt TM, Thomas JD, ACC/AHA Task Force Members (2014) AHA/ ACC guideline for the management of patients with valvular heart disease: a report of the American College of Cardiology/American Heart Association Task Force on Practice Guidelines. Circulation 129(2014):e521-643. https://doi.org/10.1161/CIR.00000 00000000031

20. Lindenfeld J, Abraham WT, Grayburn PA, Kar S, Asch FM, Lim DS, Sundareswaran KS, Weissman NJ, Mack MJ, Stone GW, MitraClip Implantation in Patients with Heart Failure and Secondary Mitral Regurgitation (The COAPT Trial): Impact of Effective Regurgitation Orifice Area and Left Ventricular Size on MitraClip Response, (n.d.)

21. Grayburn PA, Carabello B, Hung J, Gillam LD, Liang D, Mack MJ, McCarthy PM, Miller DC, Trento A, Siegel RJ (2014) Defining "severe" secondary mitral regurgitation: emphasizing an integrated approach. J Am Coll Cardiol 64:2792-2801. https://doi. org/10.1016/j.jacc.2014.10.016 